\title{
Correction of author's name: Applying a mixed methods design for needs assessment of an international fellowship training program for Mongolian health professions
}

\author{
Nomin Amgalan', Jwa-Seop Shin', Seung-Hee Lee', Oyungoo Badamdorj ${ }^{2}$ and Hyun Bae Yoon ${ }^{3}$
}

${ }^{1}$ Department of Medical Education, Seoul National University College of Medicine, Seoul, Korea, ${ }^{2}$ Division of Educational Policy and Management, Mongolian National University of Medical Sciences, Ulaanbaatar, Mongolia, and ${ }^{3}$ Office of Medical Education, Seoul National University College of Medicine, Seoul, Korea

To the Editor,

We found an error in our published article titled "Applying a mixed methods design for needs assessment of an international fellowship training program for Mongolian health professions [1]" where the corresponding author's name has been incorrectly spelled as Hyun-Bae Yoon (the hyphen should be omitted). The correct name is Hyun Bae Yoon. We apologize for any inconvenience caused.

Yours sincerely,

Hyun Bae Yoon

*DOI of original article: https://doi.org/10.3946/kjme.2019.133.

\section{References}

1. Amgalan N, Shin JS, Lee SH, Badamdorj O, Yoon HB. Applying a mixed methods design for needs assessment of an international fellowship training program for Mongolian health professions. Korean J Med Educ. 2019;31(3):227-237. https://doi.org/10.3946/kjme.2019.133.

eISSN: 2005-7288

(C) The Korean Society of Medical Education. All rights reserved.

This is an open-access article distributed under the terms of the Creative Commons Attribution Non-Commercial License (http://creativecommons.org/licenses/ by-nc/3.0/), which permits unrestricted non-commercial use, distribution, and reproduction in any medium, provided the original work is properly cited. 